\title{
Aspects Regarding the Use of 3D Printing Technology and Composite Materials for Testing and Manufacturing Vertical Axis Wind Turbines
}

\begin{abstract}
ALEXANDRU-POLIFRON CHIRIȚA ${ }^{1 *}$, PAUL-PETRU BERE ${ }^{2}$, RADU IULIAN RĂDOI ${ }^{1}$, LILIANA DUMITRESCU ${ }^{1}$
${ }^{1}$ Hydraulics and Pneumatics Research Institute INOE 2000-IHP, 14 Cuţitul de Argint Str., 040558, Bucharest, Romania

${ }^{2}$ Technical University of Cluj-Napoca, 28 Memorandum Str., 400114, Cluj-Napoca, Romania

The article presents the technology and process, whereby a small-scale demonstration model and the real-scale prototype of vertical axis wind turbine blades are produced using rapid prototyping technology $(3 D P)$ and GFRP surface coatings, which help to improve the mechanical properties. In the end of the article the results of the production process and the advantages of combining these technologies are presented.
\end{abstract}

Keywords: vertical axis wind turbine, 3D printing, polylactide, GFRP.

3D printing (3DP), specifically fused filament fabrication (FFF), is one of the most accessible and widespread rapid prototyping technologies [1-7]. Recent advances in additive manufacturing (AM), a construction technique where a three-dimensional object is created through the build-up of thin layers of a thermoplastic material, have resulted in the commercialization and popularization of what is commonly known as 3DP. [1-4, 6-8]

Objects for 3D printing are stored in digital files for modification using 3D modeling software, and are easily copied, and transferred via the Internet. Small wind turbine technology stands to benefit greatly from this technology. With the appropriate design, wind turbines could be rapidly manufactured (printed) and assembled on-site at an as needed basis without too many tools beyond a 3D printing machine and printing filament, or at least it helps a lot in creating the complicated geometry of wind turbine blades that would be quite difficult to produce with other technologies.

\section{Applications for wind energy technology}

The primary and historic application of 3D printing technology for wind turbines has been through rapid prototyping - where a model of a part for industrial manufacture is produced through the 3D printing process so that engineers and designers can test certain component properties within a controlled environment before releasing a design into full production. Typically scale models of larger components are printed. 3DP, rapid prototyping has been utilized in the sustainability technology sector to produce aerodynamic research models hydro turbine prototypes $[3,4,9]$ and recently micro-scale wind turbines. In each of these cases the printed parts were prototypes simulating the construction and shape of the manufacture-able part in different materials and construction means.

With the emergence of affordable and accessible 3DP technology there is the opportunity for wind energy to realize a second, and potentially equally impactful, benefit. By considering the approach of designing small wind turbines as a modular assembly of components for direct manufacture by a consumer level 3D printer, new opportunities are presented for decreasing cost, reducing waste and increasing accessibility for wind turbines around the world [10-14]. This approach extends beyond rapid prototyping and into rapid manufacturing, defined as the direct production of finished goods from a rapid prototyping device [15-20].

\section{Experimental part}

Materials and methods

This section presents the production process of a functional model (demonstrator) in 1:5 scale, as well as the production process of the Darrieus blades of the experimental model in 1:1 scale. They are shown in Figure 1.

*chirita.ihp@fluidas.ro, Phone: 0769.404.303 


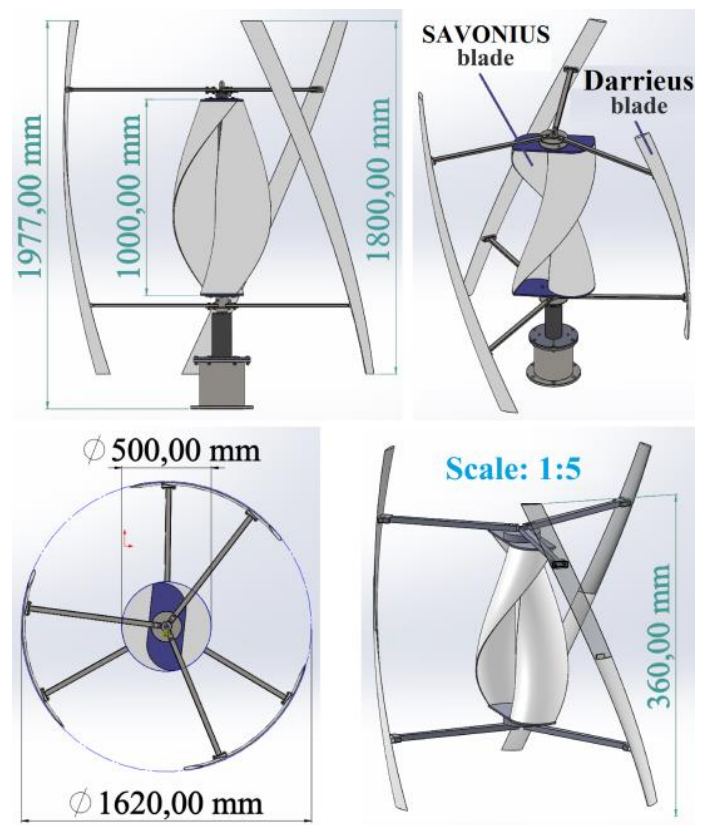

Fig. 1. 3D CAD models from the SolidWorks software of the demonstrator and the experimental model.

The prototyping process of functional model (1:5 scale).

Printing was done on the BCN3D SIGMA R19 Printer (FFF) with the following facilities:

- $\quad$ Architecture: Independent Dual Extruder (IDEX);

- Printing volume: $210 \mathrm{~mm}$ x $297 \mathrm{~mm}$ x $210 \mathrm{~mm}$;

- Heated bed maximum temperature: $100{ }^{\circ} \mathrm{C}$;

- Positioning resolution (X/Y/Z): $1.25 \mu \mathrm{m} / 1.25 \mu \mathrm{m} / 1 \mu \mathrm{m}$;

- Firmware: BCN3D Sigma - Marlin;

- Extruder system Extruder Bondtech Tм high-tech dual drive gears; Hotends: Optimized and manufactured by e3D TM;

- $\quad$ File preparation software: BCN3D Cura.

Both the printer and the slicing software of the 3D models are shown in figure 2.

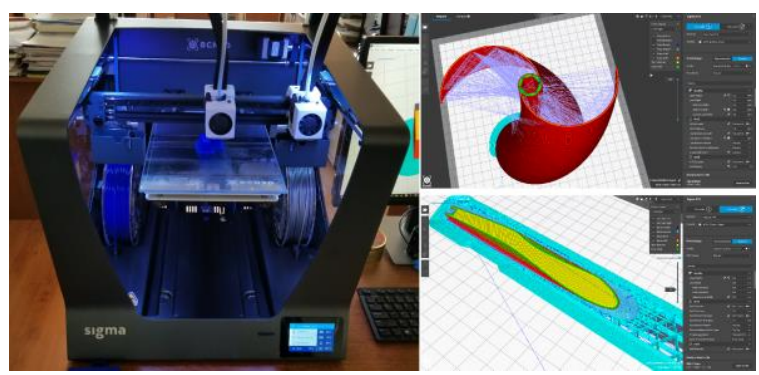

Fig. 2. SIGMA R19 Printer and BCN3D Cura software

All the parts of the functional model were printed with PLA and for the parts that needed support PVA was used, which dissolves easily in water.

Parameters of the 3D printing process: the filament diameter was $2.85 \mathrm{~mm}, 0.4 \mathrm{~mm}$ hotend diameter, $0.2 \mathrm{~mm}$ layer height, $35 \%$ or $100 \%$ infill density, $205^{\circ} \mathrm{C}$ printing temperature, $60^{\circ} \mathrm{C}$ build plate temperature and a conservative print speed of $50 \mathrm{~mm} / \mathrm{s}$.

Because the blades of the Darrieus turbine are larger than the printer can produce, they were divided into two pieces, and due to their curvature, in two planes; it was necessary to print with support material. Figure 3 shows the parts that needed support material, including the arms for the purpose of supporting the Darrieus turbine; they have practiced 2 through-holes that are necessary for the assembly with screws. 


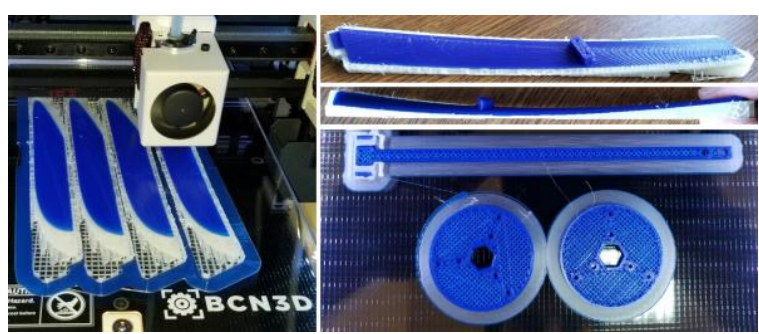

Fig. 3. The printed parts that needed support material

Figure 4 shows the parts that did not need support material during the printing process; they are: the covers of the Savonius turbine, which have practiced a channel that rigidifies the whole sub-assembly, the Savonius turbine itself, as well as the bearing base, which has the role of support for hexagonal shaft and turbine.

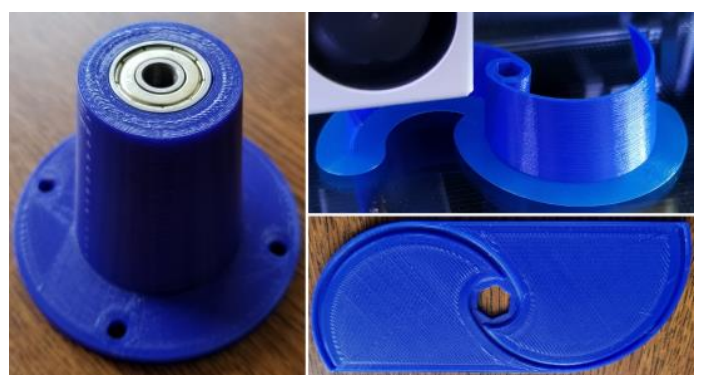

Fig. 4. Components that did not need support material during the printing process

The prototyping process of the Darrieus turbine blades in 1:1 scale

In this case, a FDM printer type LeapFrog, the Creart HS XL model was used. The platform printer dimensions are 280x270x590 mm. To obtain a prototype using FDM procedure we must follow certain steps. In the initial stage we must have a CAD model of the blade. In design process a STL file was obtained using SOLID Works software. This file contains all the information about the digital geometry of the blades. That was exported to FDM machines. The next step is to integrate the file format to FDM printer. In this step the sealing surface of the piece is divided in plethora of triangular meshes. The machine software is compatible and can separate, by usually called G (slicing) codes, the sections of the piece. To create the $\mathrm{G}$ slicing code used to make the blade prototype Ultimaker software Cura 4.0 was used. From a list of commands, the optimal parameters to obtain the prototype were chosen. The printer was started and the prototype was obtained according to the printer software evaluation time. The last step is to remove the obtained plastic piece from FDM printer platform and eliminate the additional supports.

To obtain the prototype the blade and the NACA profile were investigated. In this case we chose to make a plastic prototype. In order to have good mechanical properties of the plastic prototype Glass Fiber Reinforced Polymer GFRP layers were applied on blades [21-26]. According to the thickness of the GFRP cover layers the plastic prototype was reduced by $1 \mathrm{~mm}$ for all the section dimensions. The manufacturing strategy of the blades prototype has established that the blade was obtained by plastic material by $1 \mathrm{~mm}$ for exterior, covered by GFRP layers by $1 \mathrm{~mm}$. For interior of the blade a couple of structures were analyzed in order to obtain a good stiffness aiming to not have geometrical deformation of the blade in function time (Figure 5).

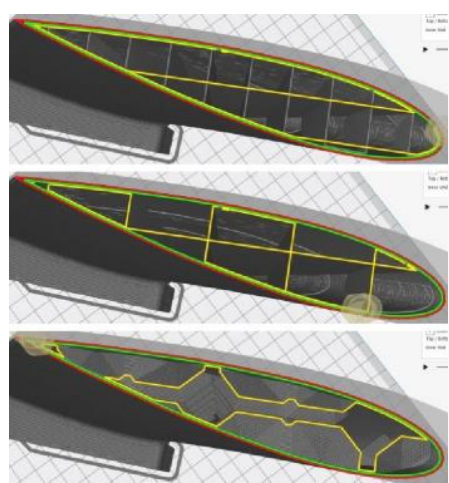

Fig. 5. Interior structure types 
At the same time the weight of the blade was evaluated. The Grid structure (figure 6) was chosen to be used for the interior. The blades contain two areas where the connections points are located. These areas are mechanically requested. The internal structures were modified. The infill of the support was $100 \%$. In this area the connections points are assembled by the rotor generator by using two screws.

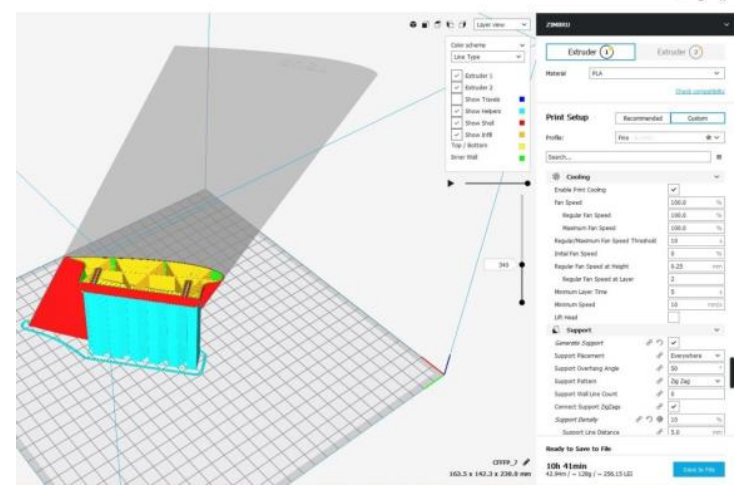

Fig. 6. Interior structure evaluation in support area of the blade and used parameters

These two parts which contain the fixing area of the blades are estimated by Cura 4.0 software FDM machine to take 10.41 hours as manufacturing time. For internal structure of the blades a $15 \%$ infill was used in order to obtain a light structure (figure 7) and the Grid structure was chosen. The material used was PLA LEAPFROG MAXX Essentials by $1.75 \mathrm{~mm}$ diameter. The extruder head nozzle diameter was $0.5 \mathrm{~mm}$ and the applied extruded plastic materials were $0.2 \mathrm{~mm}$. The printing temperature was $215^{\circ} \mathrm{C}$ for the material and the support. The printer heated plate temperature was $55^{\circ} \mathrm{C}$.

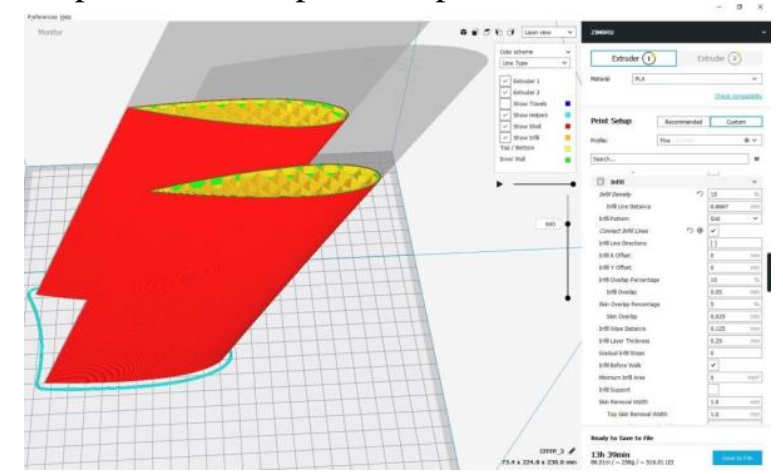

Fig. 7. Internal structure of the blades and the process parameters

The manufacturing time of the segments which do not include the connection support was 13.39 hours. The segments of the blades were assembled by Cyanoacrylate adhesive by Henkel. In order to obtain the quicker connection an activator spray was applied on bonding surface.

The manufacturing process for two blade segments produced at the same time is indicated in Figure 8 . In this case two segments are applied on the printer platform.

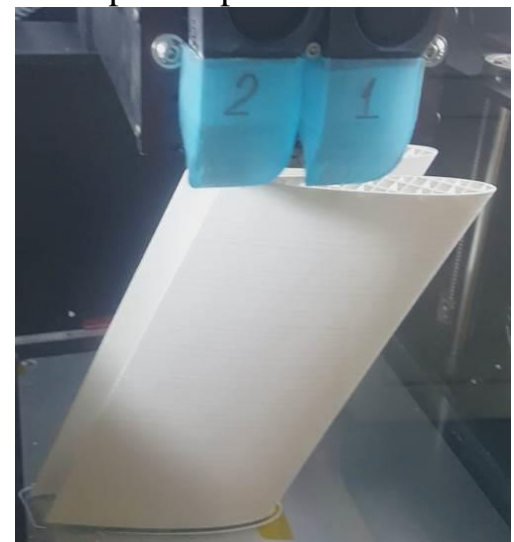

Fig. 8. Blades segments in manufacturing time by FDM process

The obtained blade from eight segments assembled was covered by GFRP layers. Three layers of glass fiber textile type Twill by $280 \mathrm{~g} / \mathrm{m}^{2}$ were used, and one by $163 \mathrm{~g} / \mathrm{m}^{2}$. The architecture of the layers was $[0 / 90 / \pm 45 / 0 / 90]-3$ layers, Twill $280 \mathrm{~g} / \mathrm{m} 2$; and for the last one [0/90] - 1 layer, Twill $163 \mathrm{~g} / \mathrm{m} 2$. For 
matrices epoxy resin type L 285 and the hardener L286 from Lange Ritter company were used. The mixing ratio was 100:35. The hand lay-up procedure was applied to laminate the GFRP material. The GFRP textiles were applied layer by layer on plastic prototype. The GFRP layers were fixed by epoxy spray like in Figure 9. In the final stage the epoxy resin was applied and it impregnated all the layers. Supplementary a pressure by a roll was applied to homogenize the resin excess. In the end, the wet GFRP was covered by Peel-ply by $163 \mathrm{~g} / \mathrm{m} 2$ by Nylon material.

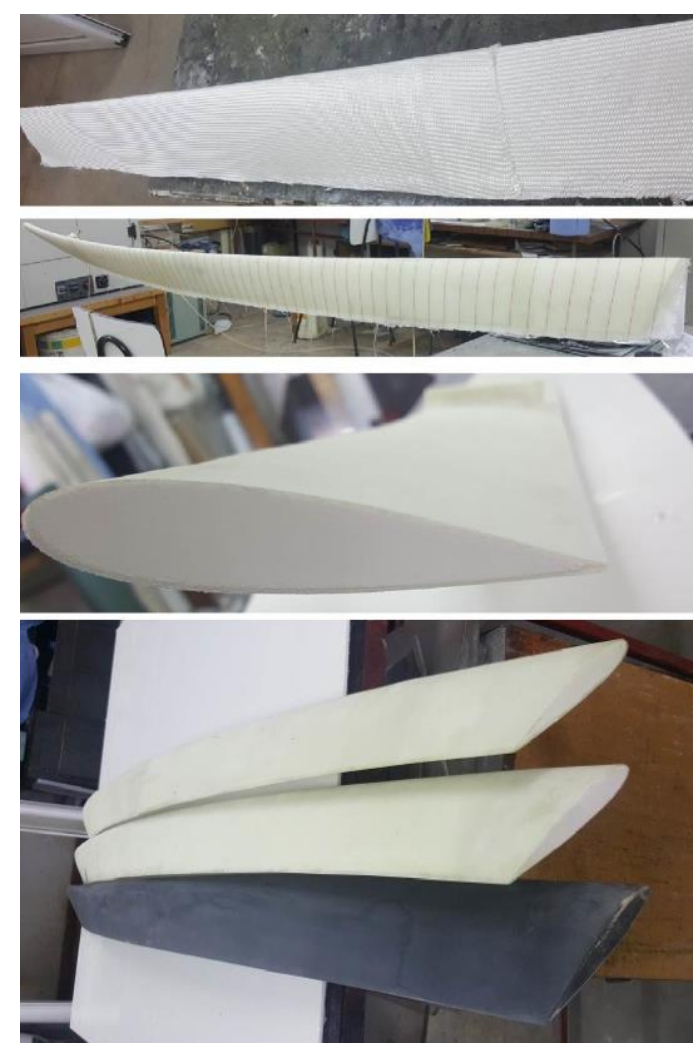

Fig. 9. GFRP cover layers process

The curing time was 12 hours at $25{ }^{\circ} \mathrm{C}$ and 12 hours at $80{ }^{\circ} \mathrm{C}$ in the oven. After complete polymerization and heat treatment the peel-ply material were rejected. The borders of the blades were cut at the final dimension.

The obtained surface was covered by Acrylic filler. Three sprayed layers were applied. Between the filler layers the surfaces were sanded by abrasive paper from 400-600 grit and at the final 1000 grit. The finished surface was painted by the acrylic painting.

The weight of the obtained plastic PLA blade prototype was $905 \mathrm{~g}$. The final weight of the blade was $1400 \mathrm{~g}$.

Weight fraction ratio

The weight fraction ratio $W_{f}$ is defined by:

$$
W_{f}=\frac{w_{f}}{w_{c}} \text { - "weight fraction ratio" }
$$

Where noted: $\mathrm{w}_{\mathrm{f}}$ - fiber weight;

$\mathrm{W}_{\mathrm{c}}$ - composite weight.

The obtained weight fraction ratio for GFRP material was 50\%. Three blades for a vertical axis wind turbine were obtained using this procedure. The obtained results are presented in Figure 9.

\section{Experimentation of the functional model}

After all the parts of the 1:5 scale wind turbine were produced, they were assembled to demonstrate the functionality of the electricity generation system. Figure 10 shows the electromechanical diagram of the demonstrator test stand. 


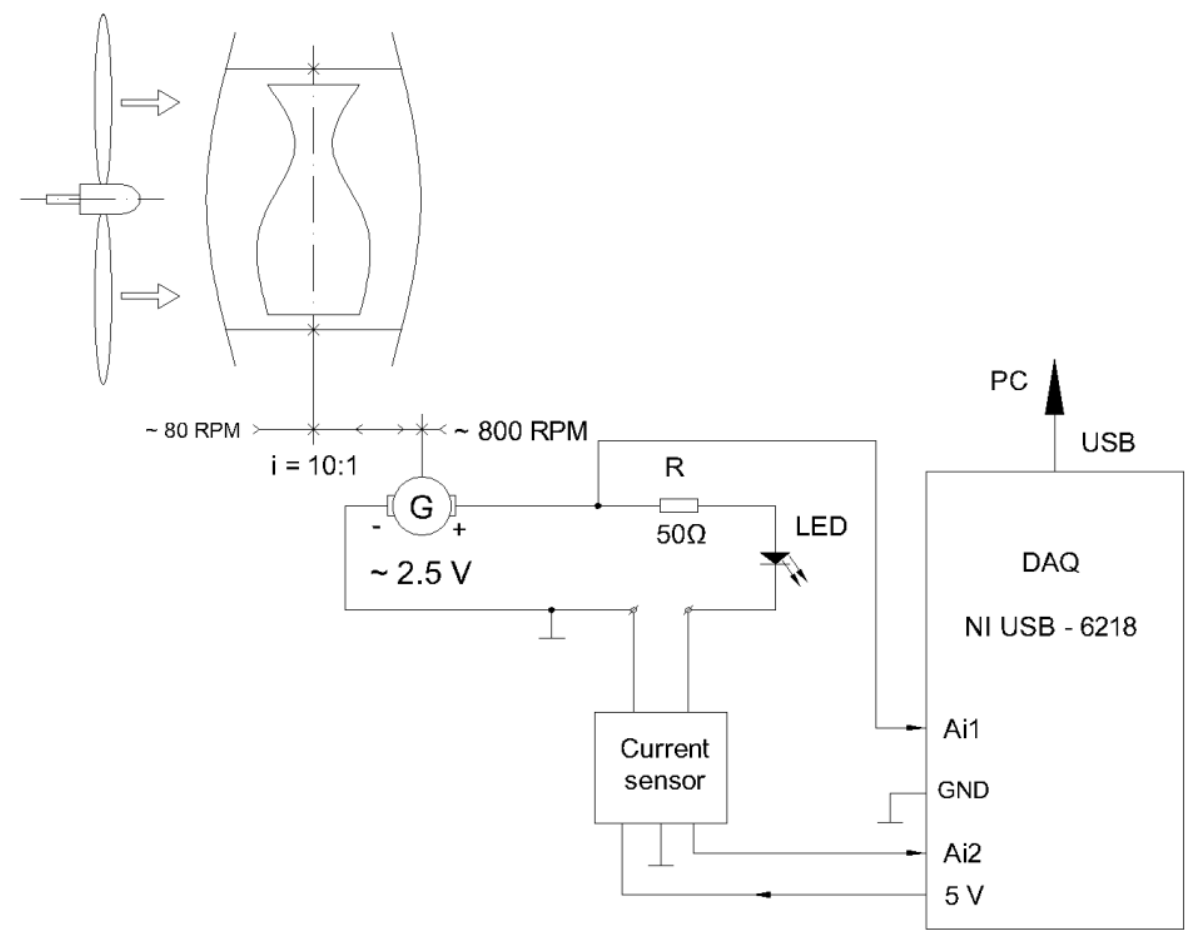

Fig. 10. Electromechanical diagram of the experimental installation

The structure of the stand can be seen in figure 11. The industrial fan generates an air current that drives the wind turbine; its shaft is connected to the electric generator by means of a transmission through the belt, and the measurement of the values of voltage and current produced by the turbine were carried out with the help of a current sensor and the experimental data acquisition board.

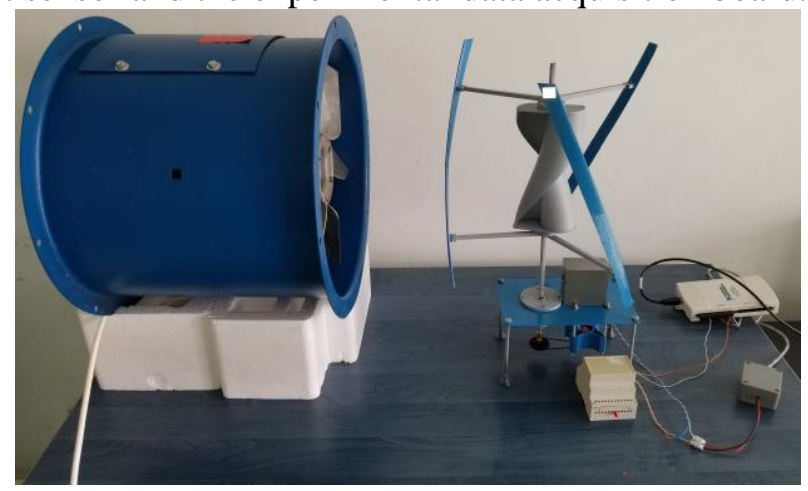

Fig. 11. Experimental installation

\section{Results and discussions}

With the help of the experimental installation, presented in figure 11, the following experimental results were acquired:

- The speed of the wind turbine rotor was measured with the help of the tachometer without contact and its speed can be noticed in figure 12 .

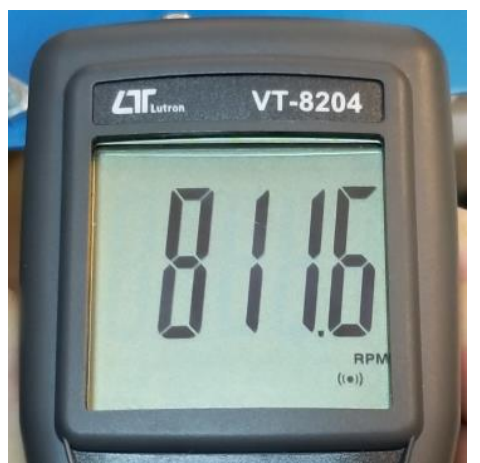

Fig. 12. Rotation speed of the wind turbine 
- The values of the voltages and the current produced by the wind turbine as well as their variation in time due to the moment of inertia of the rotor and the entire transmission are shown in figure 13.
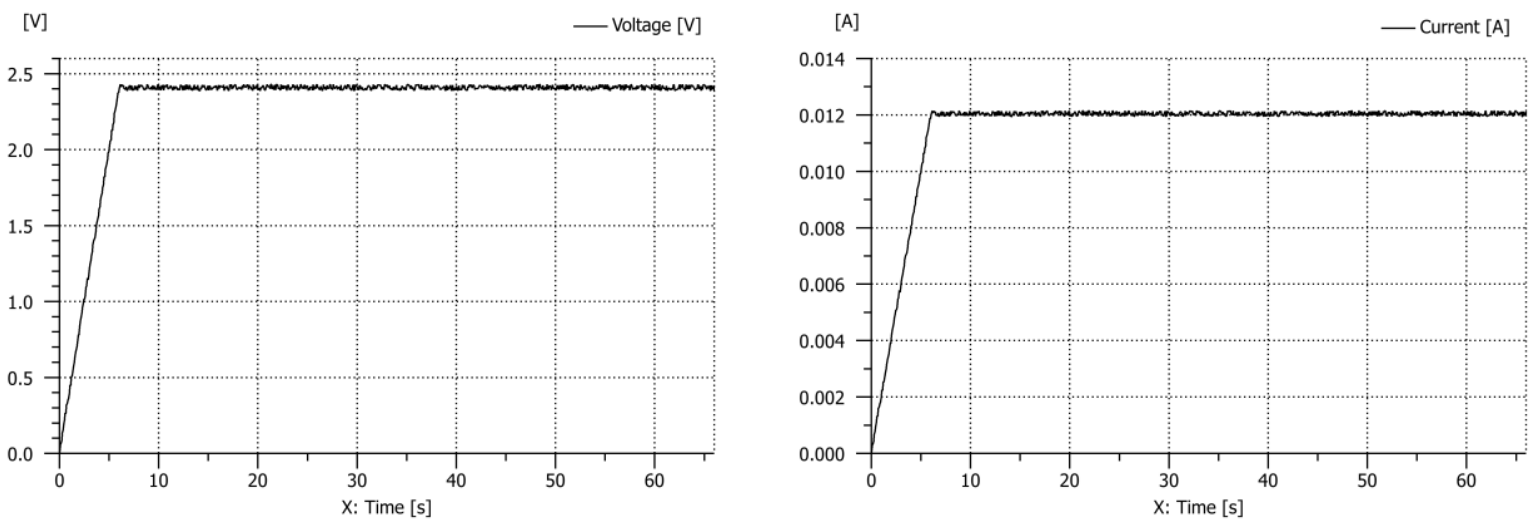

Fig. 13. Values of the voltages and the current produced by the wind turbine

Figure 14 shows on the left side, the functional model of the wind turbine, and on the right side, the prototype of turbine blades of the experimental model mounted on a metal structure.

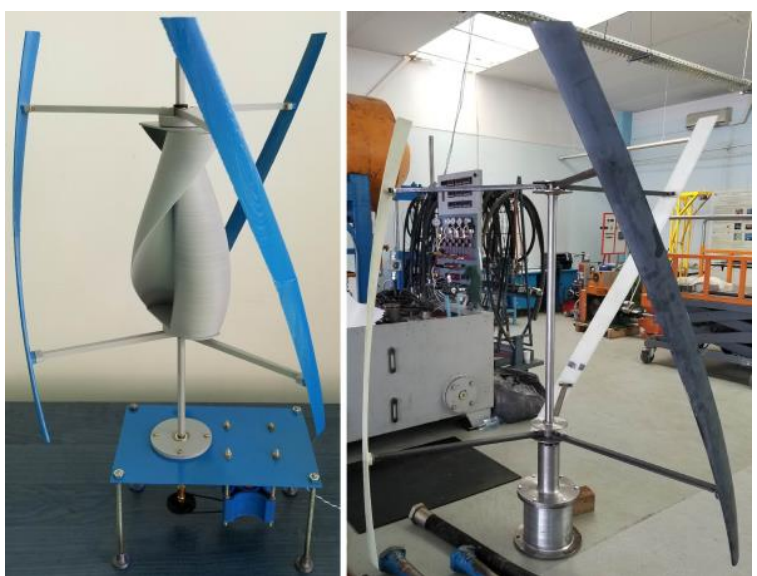

Fig. 14. The functional model (lt.) and the experimental model (rt.)

\section{Conclusions}

3DP technology excels at such tasks; it manages to describe in detail the profiles of the blades, and with the help of various coating processes they can become more mechanically resistant.

Due to the additive nature of this technology, wind turbine rotors can be created, much lighter than the classical processes. They have a lower moment of inertia, and because of this the turbines can start operating at lower wind speeds.

Since the experimental model is still not finished, the results of tests to be conducted on it will be presented in further research.

Acknowledgements: This paper has been funded by the Romanian Ministry of Research and Innovation under Programme IDevelopment of national R\&D system, Subprogramme 1.2 - Institutional performance - Projects financing excellence in $R \& D+I$, Financial Agreement no. 19PFE/17.10.2018.

\section{References}

1. VASILESCU, M.D., FLESER, T., Mat. Plast., 55, no. 2, 2018, p. 247

2. POPESCU, A., ENCIU, G., DOBRESCU, T., PASCU, N. E., Mat. Plast., 55, no. 1, 2018, p. 20

3. NEDELCU, D., COJOCARU, V., MICU, L.M., FLOREA, D., HLUSCU, M., Mat. Plast., 56, no. 2, 2019, p. 454

4. .NEDELCU, D., BARA, A., PELLAC, A., BOGDAN, S.L., Mat. Plast., 54, no. 3, 2017, p. 443

5. COSMA, C., ROTAR, D., CIOANA, C., SERBAN, I., Mat. Plast., 48, no. 3, 2011, p. 259

6. NEDELCU, D., COJOCARU, V., GHICAN, A., PERIS-BENDU, F., AVASILOAIE, R., Mat. Plast., 52, no. 4, 2010 , p. 475

7. STAN, D., TULCAN, A., COSMA, C., The "Industrial Engineering" profile and competences, Proc. of the 14th Intern. Conf. on Modern Technologies, Quality and Innovation (ModTech 2010), Slanic-Moldova, Romania, 20-22 May 2010, pp. 543-546

8. BASSETT, K., CARRIVEAU, R., TING, D.S.-K., Sustain. Energy Technol. Assess., 11, 2015, p. 186

9. POPESCU, T.C., DUMITRESCU, C., BORDEASU, I., Mat. Plast., 53, no. 1, 2016, p. 174

10. MOHAMED, M.H., ALI, A.M., HAFIZ, A.A., Eng. Sci. Technol., Int. J., 18, no. 1, 2015, p. 1 
11. SABAEIFARD, P., RAZZAGHI, H., FOROUZANDEH, A., Determination of vertical Axis wind turbines optimal configuration through CFD simulations, Proc. of 2012 2nd Intern. Conf. on Future Environment and Energy (ICFEE 2012), Singapore, 26-28 February 2012, pp. 109-113

12. PONTA, F.L., SEMINARA, J.J., OTERO, A.D., Renew. Energ., 32, no. 1, 2007, p. 35

13. CASTELli, M.R., ENGLARO, A., BENINI, E., The Darrieus wind turbine: proposal for a new performance prediction model based on CFD, Energy, 36 pp. 4919-4934, 2011

14. UDROIU, R., NEDELCU, A., DEAKY, B., Environ. Eng. Manag. J., 10, no. 9, 2011, p. 1387

15. POOLE, S., PHILLIPS, R., Rapid prototyping of small wind turbine blades using additive manufacturing, Pattern Recognition Association of South Africa and Robotics and Mechatronics International Conference (PRASA-RobMech), Port Elizabeth, South Africa, 25-26 November 2015, pp. 189-194

16. ROŞCULET,, R.-T., FETECĂU, C., J. of Engineering Sciences and Innovation, 3, no. 1, 2018, p. 15

17. NOVAKOVA-MARCINCINOVA, L., KURIC, I., Manuf. and Ind. Eng., 11, no. 1, 2012, p. 24

18. BORDONI, M., BOSCHETTO, A., Rapid Prototyp. J., 18, no. 4, 2012, p. 308

19. ADAM, G., ZIMMER, D., Rapid Prototyp. J., 21, no. 6, 2015, p. 662

20. CAMPBELL, R.I., COMBRINCK, J., BARNARD, L., Rapid Prototyp. J., 14, no. 5, 2008, p. 271

21. BEJ, A., BORDEASU, I., MILOS, T., BADARAU, R., Mat. Plast., 49, no. 3, 2012, p. 212

22. MILOS, T., BORDEASU, I., BADARAU, R., BEJ, A., BORDEASU, D., Mat. Plast., 50, no. 4, 2013, p. 279

23. DZIEDZIC, K., ZUBRZYCKA-WRÓBEL, J., JÓZWIK, J., BARSZCZ, M., SIWAK, P., CHAŁAS, R., Adv. Sci. Technol. Res. J., 10, no. 32, 2016, p. 144

24. BERE, P., KROLCZYK, J.B., Determination of mechanical properties of carbon/epoxy plates by tensile stress test, Proc. of Int. Conf. Energy, Environment and Material Systems (EEMS 2017), Polanica-Zdrój, Poland, 13-15 September 2017, 19, DOI: $10.1051 / \mathrm{e} 3$ sconf/20171903018

25. ENACHESCU, G., STEFANESCU, M.F., Mat. Plast., 53, no. 2, 2016, p. 198

26. AZHAGUVEL, N., CHARLES, S., MOULEESWARAN, S., T. Can. Soc. Mech. Eng., 41, no. 3, 2017, p. 375

Manuscript received: 22.10 .2019 